\title{
Global Dust Optical Depth Climatology Derived from CALIOP and MODIS Aerosol Retrievals on Decadal Time Scales: Regional and Interannual Variability
}

\author{
QIANQIAN SONG ${ }^{1}$, ZHIBO ZHANG $^{1}$, HONGBIN YU $^{2}$, \\ PAUL GINOUX ${ }^{3}$ AND JERRY SHEN ${ }^{2}$ \\ ${ }^{1} \mathrm{UMBC}$ \\ ${ }^{2}$ NASA Goddard Space Flight Center \\ ${ }^{3}$ NOAA Geophysical Fluid Dynamics Laboratory (GFDL) \\ Presenting Author: zzbatmos@umbc.edu
}

We present a satellite-derived global dust climatological record over the last two decades, including the monthly mean visible dust optical depth (DAOD) and vertical distribution of dust extinction coefficient at a $2^{\circ}$ (latitude) $\times 5^{\circ}$ (longitude) spatial resolution derived from CALIOP and MODIS. Dust is distinguished from non-dust aerosols based on particle shape information (e.g., lidar depolarization ratio) for CALIOP, and on dust size and absorption information (e.g., fine-mode fraction, Angstrom exponent, and single-scattering albedo) for MODIS, respectively. On multi-year average basis, the global $\left(60^{\circ} \mathrm{S}-60^{\circ}\right.$ $\mathrm{N})$ and annual mean DAOD is 0.029 and 0.063 derived from CALIOP and MODIS retrievals, respectively. In most dust active regions, CALIOP DAOD generally correlates well with the MODIS DAOD, with CALIOP DAOD being significantly smaller. CALIOP DAOD is $18 \%, 34 \%, 54 \%$ and $31 \%$ smaller than MODIS DAOD over Sahara Deserts, the tropical Atlantic Ocean, the Caribbean Sea, and the Arabian Sea, respectively. Over East Asia and the northwestern Pacific Ocean (NWP), however, the two datasets show weak correlation. Despite these discrepancies, CALIOP and MODIS show similar seasonal and interannual variations in regional DAOD. For dust aerosol over NWP, both CALIOP and MODIS show a declining trend of DAOD at a rate of about $2 \% \mathrm{yr}^{-1}$. This decreasing trend is consistent with the observed declining trend of DAOD in the southern Gobi Desert at a rate of $-3 \% \mathrm{yr}^{-1}$ and $-5 \% \mathrm{yr}^{-1}$ according to CALIOP and MODIS, respectively. The decreasing trend of DAOD in the southern Gobi Desert is in turn found to be significantly correlated with an increasing trend of vegetation and a decreasing trend of surface wind speed in the area. 